Check for updates

Cite this: RSC Adv., 2019, 9, 17988

Received 23rd April 2019 Accepted 2nd June 2019

DOI: 10.1039/c9ra03023a

rsc.li/rsc-advances

\section{Polysaccharides from Polygonatum sibiricum Delar. ex Redoute induce an immune response in the RAW264.7 cell line via an NF- $\kappa$ B/MAPK pathway}

\begin{abstract}
Jiaozhen Zhang, ${ }^{a} \mathrm{Na} \mathrm{Liu},{ }^{a}$ Chao Sun, ${ }^{\text {bc }}$ Deqing Sun ${ }^{\star b c}$ and Yongjie Wang (iD *c
The aim of this study was to examine the effect of polysaccharides from Polygonatum sibiricum (PSP) on RAW 264.7 cells together with the underlying signaling pathways. Water-soluble polysaccharides were extracted from Polygonatum sibiricum and the immunological activity/mechanism was explored in depth in RAW 264.7 cells. Our results demonstrated that PSP induced dendritic-like morphological changes in RAW 264.7 cells, and increased the production of nitric oxide, TNF- $\alpha$ and IL- 6 in a dose-dependent manner. Mechanistic studies revealed that PSP promoted the accumulation of TNF- $\alpha$ and IL- 6 mRNA and caused $1 \kappa \mathrm{B}-\alpha$ degradation and NF- $\kappa \mathrm{B}$ p65 translocation into the nucleus at both the transcriptional and translational levels. The expression of iNOS, COX-2, NF- $\mathrm{B}$ and phosphorylated p38 MAPK was upregulated in PSP-treated RAW 264.7 cells. Water-soluble polysaccharides possess immunological activity and the immunostimulatory mechanism may be attributed to the NF- $\kappa B$ and p38 MAPK pathways similar to the mechanism of lipopolysaccharides.
\end{abstract}

\section{Introduction}

In older individuals, the immune system is weakened by the aging process, stress, or disease. These deficiencies could be addressed by enhancing the immune response using natural or chemical adjuvants with immunomodulatory properties, whereas repeated administration of chemical pharmaceuticals can cause side effects. ${ }^{1}$ In the last decade, polysaccharides have drawn the attention of chemists and immunobiologists for their immunomodulatory and antitumor properties since they are typically nontoxic and do not cause significant side effects. Many polysaccharides have been isolated from natural sources, such as plants, microbes and algae. Natural polysaccharides have long been appreciated for their potent immunostimulatory activity and could be potential candidates as immunomodulators with wide applications. ${ }^{2}$

Macrophages are important effector cells involved in surveillance, chemotaxis, phagocytosis and destruction of targeted organisms in a healthy immune system, they play vital roles in the host defense system against external stimuli and tumors. $^{3}$ An important mechanism involved in the immune stimulatory activity of polysaccharides is their ability to enhance macrophage function. ${ }^{4}$ Bioactive polysaccharides can bind to

${ }^{a}$ Department of Natural Products Chemistry, Key Lab of Chemical Biology of Ministry of Education, Shandong University, Jinan, Shandong 250012, PR China

${ }^{b}$ Department of Pharmacology, School of Pharmaceutical Sciences, Shandong University, Jinan, Shandong 250012, PR China. E-mail: sundq0405@126.com

'Department of Pharmacy, The Second Hospital of Shandong University, Shandong University, Jinan, Shandong 250033, PR China. E-mail: jalaf64@126.com pattern recognition receptors (PRRs) on the surface of macrophages, such as toll-like receptors (TLRs) and complement receptor type 3 (CR3), and subsequently trigger several signaling pathways to activate macrophages. ${ }^{5}$ NF- $\mathrm{\kappa B}$ and p38 MAPK signaling pathways play important roles in this activation process. ${ }^{6} \mathrm{NF}-\mathrm{\kappa B}$ is a key transcription factor that can promote the expression of variety of molecules involved in immune, inflammatory and acute phase responses, including nitric oxide (NO) and TNF- $\alpha .{ }^{7}$ p38 MAPK regulates the expression of proinflammatory molecules, especially TNF- $\alpha$ and other components of the immune system. ${ }^{8}$ Our previous study demonstrated that a polysaccharide called PSP, isolated from Polygonatum sibiricum possessed chemoprotective effects on immunosuppression caused by cyclophosphamide (Cy) treatment, ${ }^{9}$ but the underlying mechanism is still unclear. In this study, we investigated the immunostimulatory effect of PSP on RAW 264.7 cells and set out to uncover its possible mechanisms.

\section{Results}

\subsection{Physicochemical properties}

After pretreatment and extraction by hot water extraction and alcohol sedimentation, the crude polysaccharides of Polygonatum sibiricum (PSP) were obtained. The mass content of PSP was designated to be approximately $4.45 \%(\mathrm{w} / \mathrm{w})$ of the dried powder. Dry PSP was a pale yellow solid and soluble in water and had no absorbance peak at 260 and $280 \mathrm{~nm}$ in the UV spectrophotometer. The identification results of PSP are shown in Table 1, which indicates the absence of proteins, nucleic acids and free reducing monosaccharides. It has been reported 
Table 1 Identification results of PSP

\begin{tabular}{|c|c|c|c|c|c|}
\hline \multirow{2}{*}{$\frac{\text { Identification }}{\text { Reaction }}$} & \multicolumn{2}{|c|}{ Polysaccharide } & \multicolumn{3}{|l|}{$\underline{\text { Protein }}$} \\
\hline & Fehling & Molisch & Precipitation & Biuret & Ninhydrin \\
\hline Deionized water & - & - & - & - & - \\
\hline PSP & - & + & - & - & - \\
\hline Hydrolyzed PSP & + & + & & & \\
\hline Glucose & + & + & & & \\
\hline BSA & & & + & + & + \\
\hline
\end{tabular}

that lipopolysaccharides (LPS) may be involved in plant polysaccharides, but at a low level. In addition, the polysaccharides extracted from Polygonatum sibiricum have reported that there was no LPS involved and no effect on activity evaluation. ${ }^{9-12}$ The total carbohydrate content of PSP as determined by the anthrone-sulfuric acid method showed $35.06 \%(\mathrm{w} / \mathrm{w})$ of polysaccharides using glucose as a standard, which mainly consisted of galactose (Gal, 63.50\%) and rhamnose (Rha, 25.14\%) accompanied by lower amounts of mannose (Man, 8.04\%), glucose (Glu, 1.75\%) and xylose (Xyl, 1.57\%). ${ }^{9}$ The average molecular weight of PSP fractions is shown in Table 2.

\subsection{Radical scavenging activity}

The radical scavenging activity of PSP was measured using the DPPH and ABTS method according to previous studies. ${ }^{13,14}$ The DPPH scavenging activity of PSP solutions was measured at different concentrations $(0.1,0.2,0.5,1.0,2.0,3.0,5.0$ and $10.0 \mathrm{mg} \mathrm{mL}{ }^{-1}$ ). As depicted in Fig. 1, the radical scavenging activity of PSP was related to the concentration of the sample solutions. A higher concentration resulted in an increased scavenging capacity. We observed that the scavenging activity was increased significantly with an increased concentration of PSP. For instance, the scavenging activities of the PSP were determined to be $69.01 \%$ and $82.58 \%$ for the DPPH and ABTS method, respectively. The results demonstrated that the polysaccharides isolated from Polygonatum sibiricum can effectively scavenge free radicals. Vitamin $\mathrm{C}(\mathrm{Vc})$ was used as a positive control.

\subsection{Cell viability determination by MTT and LDH assays}

To exclude the possibility that the potential immune regulation effect of PSP may come from the inhibition of cell proliferation
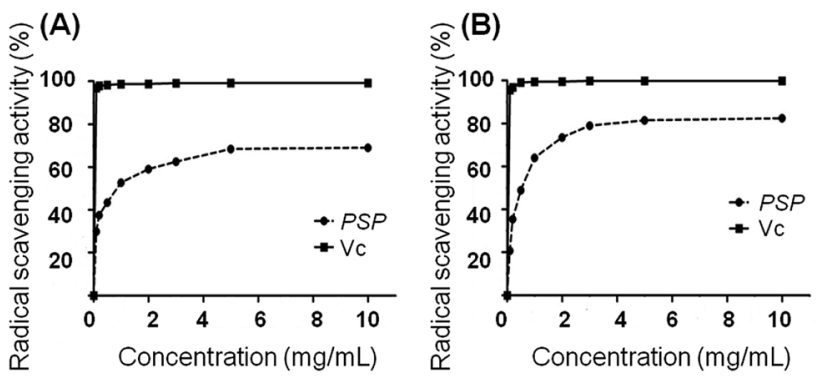

Fig. 1 Radical scavenging activity: (A) DPPH method; (B) ABTS method.

or cytotoxicity, MTT and LDH cytotoxicity assays were carried out following incubation of the cells with PSP. As shown in Fig. 2A, no effects on cell viability or proliferation as assayed by MTT were noted in the concentration range of $0-400 \mu \mathrm{g} \mathrm{mL} \mathrm{m}^{-1}$. The release of LDH from cells to the medium was measured as another marker for cell viability and is less influenced by cellular proliferation. As shown in Fig. 2B, the LDH assay demonstrated that there were no effects of PSP on the cell viability of RAW 264.7 cells at concentrations that might elicit cytokine secretions. These LDH cytotoxicity assay results are consistent with the results of the MTT assay, which indicated that PSP was nontoxic to RAW 264.7 cells.

\subsection{Effects of PSP on morphology}

As shown in Fig. 3, the normal morphology of RAW 264.7 cells was round and a few cells were fusiform in the control group.
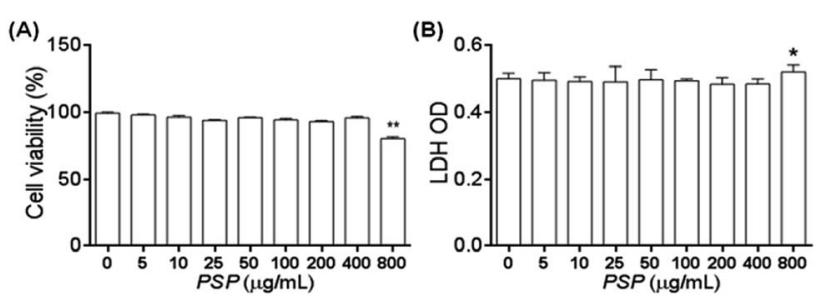

Fig. 2 The effect of PSP on the cell viability of RAW 264.7 cells (A and $B$ ) as revealed by the MTT and LDH assays, respectively. The results are represented as the mean $\pm \mathrm{SD}, n=3 . * p<0.05, * * p<0.01$, compared to control group.

Table 2 Molecular weight, chemical composition of polysaccharides ${ }^{a}$

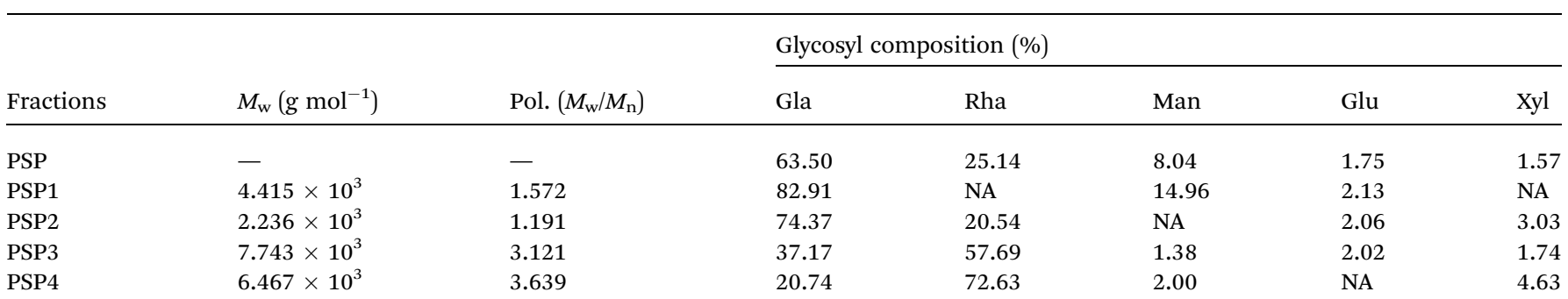

${ }^{a}$ Abbreviations: Pol., polydispersity; Car., carbohydrate; Prot., protein; U.A., nucleic acid; NA, no available; -, not detected; Gla, galactose; Rha, rhamnose; Man, mannose Glu, glucose; Xyl, xylose. 
After treatment with LPS $\left(1 \mu \mathrm{g} \mathrm{mL} \mathrm{L}^{-1}\right)$ for $12 \mathrm{~h}$, nearly half of the cells showed polygonal and dendritic-like morphology. The PSPtreated cells showed similar morphological changes as the LPStreated group. These results consistent with the enhanced functions of RAW 264.7 cells determined in our previous study.

\subsection{Effect of PSP on the production of NO}

NO production can be used as a proxy for the polysaccharidebased activation of macrophages. As shown in Fig. 4, 100-400 $\mu \mathrm{g} \mathrm{mL} \mathrm{L}^{-1}$ PSP can significantly stimulate the production of NO in RAW 264.7 cells in a dose-dependent manner. Especially in 400 $\mu \mathrm{g} \mathrm{mL} \mathrm{L}^{-1}$, the production of NO was similar to that of positive control group (LPS, $1 \mu \mathrm{g} \mathrm{mL}{ }^{-1}$ ). The increasing production of NO suggests that PSP may activate the immune-activity of macrophages.

\subsection{Effect of PSP on TNF- $\alpha$ and IL-6 levels}

To elucidate whether the polysaccharide fraction can classically activate the macrophages, we measured the amount of TNF$\alpha$ and IL- 6 secreted by RAW 264.7 cells. LPS was the most potent signal to induce the production of TNF- $\alpha$ by macrophages. In this study, after $24 \mathrm{~h}$ of incubation with LPS, $581.60 \mathrm{pg} \mathrm{mL}^{-1}$ of TNF- $\alpha$ was secreted into the cell culture media (Fig. 5A and B). The TNF- $\alpha$ concentration after incubation with $400 \mu \mathrm{g} \mathrm{mL}$ PSP (PSP-H) was $190.21 \mathrm{pg} \mathrm{mL}^{-1}$. These two values were significantly higher than the value in untreated cells. In response to cytokines such as TNF- $\alpha$ and IL-4, macrophages secrete IL-6. In this study, $504.03 \mathrm{pg} \mathrm{mL}^{-1}$ of IL-6 was secreted into the culture media after $24 \mathrm{~h}$ of incubation with LPS. Comparably, PSP-H caused the production of $162.04 \mathrm{pg} \mathrm{mL}^{-1}$ of IL-6, which was significantly higher than that produced in untreated cells.

\subsection{Effect of PSP on TNF- $\alpha$ and IL-6 mRNA accumulation}

To investigate whether the inhibitory effect of PSP on TNF- $\alpha$ and IL-6 protein production occurred at the transcriptional level, we examined the steady-state level of mRNA encoding TNF- $\alpha$ and IL-6 in RAW264.7 cells using reverse transcription polymerase chain reaction (RT-PCR). The total levels of TNF- $\alpha$ and IL-6 mRNA in the untreated and treated cell samples are depicted in Fig. 5C and D. The results demonstrated that LPS and PSP caused a significant elevation of TNF- $\alpha$ and IL- 6 mRNA. This

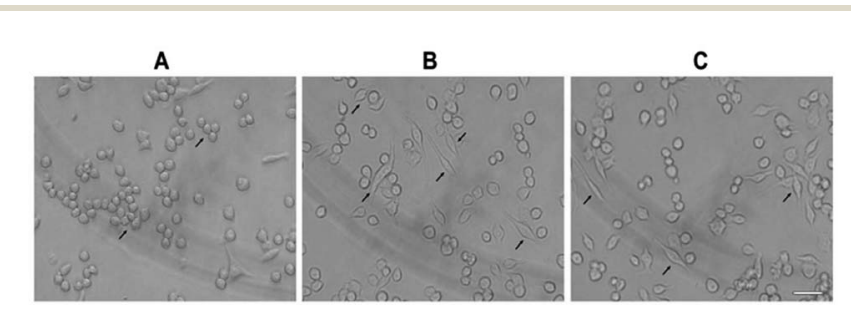

Fig. 3 The effect of PSP on morphological changes ( $\nearrow$ ) of RAW 264.7 cells. Cells were treated with PSP $\left(400 \mu \mathrm{g} \mathrm{mL}^{-1}\right)$ or LPS $\left(1 \mu \mathrm{g} \mathrm{mL} \mathrm{L}^{-1}\right)$ for $12 \mathrm{~h}$. The morphological changes were observed by inverted microscope (Olympus, Japan). (A) Control group, (B) positive control group, (C) PSP $\left(400 \mu \mathrm{g} \mathrm{mL}^{-1}\right)$ treated group. Scale bar $=10 \mu \mathrm{m}$.

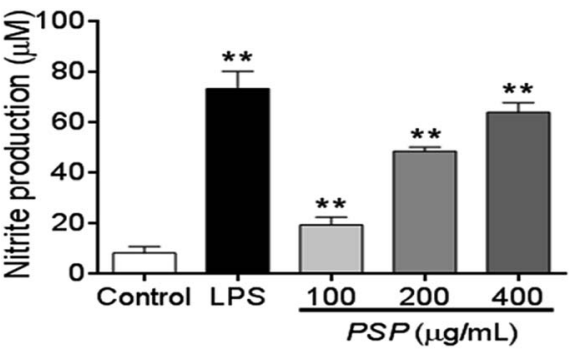

Fig. 4 Effect of PSP on nitric oxide production in RAW 264.7 cells. Cells were incubated with increasing concentrations of PSP $(100,200$, $\left.400 \mu \mathrm{g} \mathrm{mL} \mathrm{m}^{-1}\right)$ or LPS $\left(1 \mu \mathrm{g} \mathrm{mL} \mathrm{m}^{-1}\right)$ for $24 \mathrm{~h}$. Values are expressed as means $\pm S D, n=3$. ${ }^{*} p<0.01$, compared to control group.

finding further demonstrates that the cytokine release effect of PSP is mediated not only in the cellular level but also at the transcriptional level.

\subsection{Changes in the distribution of NF- $\mathrm{B}$ (p65)}

To identify the transcription factors that are activated by LPS and PSP stimulation, the DNA-binding activity of NF- $\kappa \mathrm{B}$ was measured using immunocytochemistry. Analysis of the subcellular distribution of NF- $\kappa$ B p65 in RAW 264.7 cells is shown in Fig. 6. In untreated cells, NF- $\kappa \mathrm{B}$ p65 was predominantly localized in the cytoplasm. The stimulation of RAW 264.7 cells with LPS $\left(1 \mu \mathrm{g} \mathrm{mL}{ }^{-1}\right)$ and PSP $\left(400 \mu \mathrm{g} \mathrm{mL}^{-1}\right)$ for $24 \mathrm{~h}$ caused the translocation of NF- $\kappa$ B p65 into the nucleus. And the expression of NF- $\kappa$ B p65 in cells were significantly increased treated with LPS and PSP. These results further indicate that PSP can activate the nuclear transcription factor NF- $\mathrm{B}$ in RAW 264.7 cells.

\subsection{Western blot analysis}

As shown in Fig. 7, both LPS $\left(1 \mu \mathrm{g} \mathrm{mL} L^{-1}\right)$ and PSP $\left(400 \mu \mathrm{g} \mathrm{mL} L^{-1}\right)$ caused significant phosphorylation of p38 MAPK. This result suggests that PSP can activate the p38 MAPK pathway in RAW
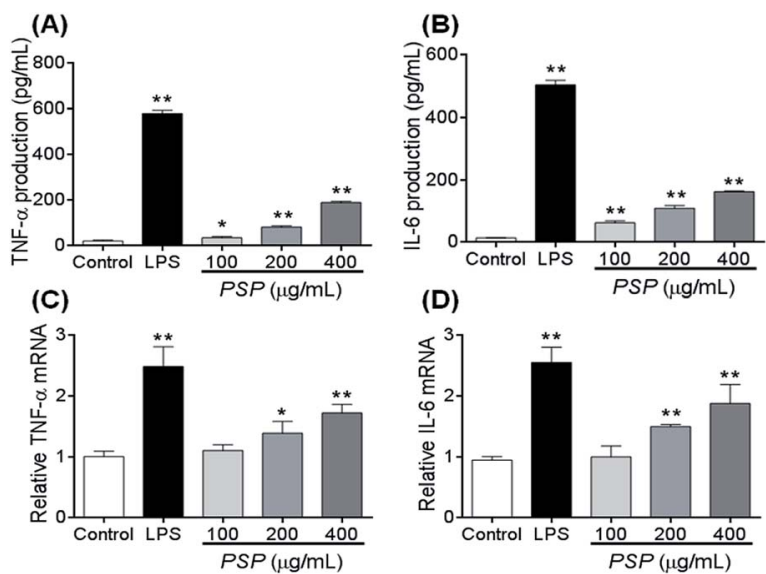

Fig. 5 Effect of PSP on TNF- $\alpha$ and IL- 6 production (A and B) and the steady-state levels of TNF- $\alpha$ and IL-6 mRNA (C and D) in RAW 264.7 cells. Cells were incubated with increasing concentrations of PSP $(100$, 200 , or $\left.400 \mu \mathrm{g} \mathrm{mL}^{-1}\right)$ or LPS $\left(1 \mu \mathrm{g} \mathrm{mL}^{-1}\right)$ for $24 \mathrm{~h}$. Values are expressed as mean $\pm \mathrm{SD}, n=3$. ${ }^{* *} p<0.01$, compared to the control group. 


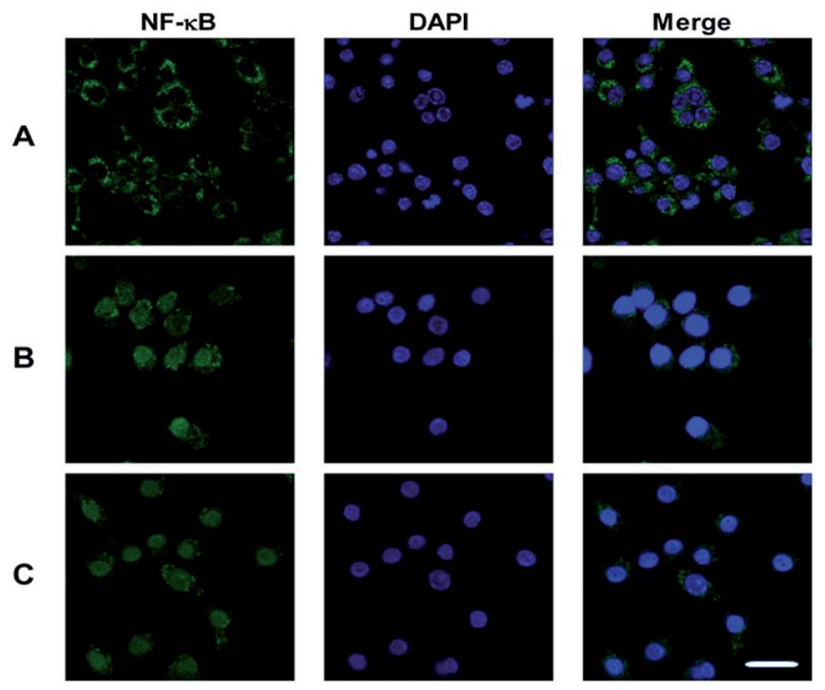

Fig. 6 Nuclear translocation of NF- $\kappa B$ p 65 visualized by immunocytochemistry. (A) Control group, (B) positive control group, (C) PSP (400 $\mu \mathrm{g} \mathrm{mL}^{-1}$ ) treated group. Scale bar $=10 \mu \mathrm{m}$.

264.7 cells. IKB- $\alpha$ is phosphorylated leading to degradation via ubiquitination. The liberated NF- $\kappa \mathrm{B}$ dimer is translocated to the nucleus resulting in the transcription of target genes. Activation of NF- $\mathrm{B}$ is contingent upon phosphorylation, poly-

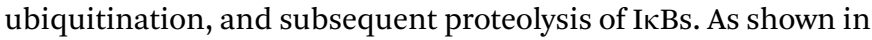
Fig. 7, both LPS $\left(1 \mu \mathrm{g} \mathrm{mL}{ }^{-1}\right)$ and PSP $\left(400 \mu \mathrm{g} \mathrm{mL} \mathrm{m}^{-1}\right)$ significantly

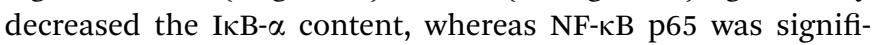
cantly increased. The detection result of NF- $\mathrm{KB}$ P65 was accordant to that of the above immunocytochemistry. To validate the NO and TNF- $\alpha$ data, the presence of iNOS and COX-2 in the cell lysate of polysaccharide-treated RAW 264.7 cells was determined. NO is synthesized by iNOS, which is absent in resting macrophages. iNOS and COX-2 were upregulated in both LPSand PSP-treated cells but not in untreated cells. This result suggests that PSP can activate the pathway in RAW 264.7 cells.
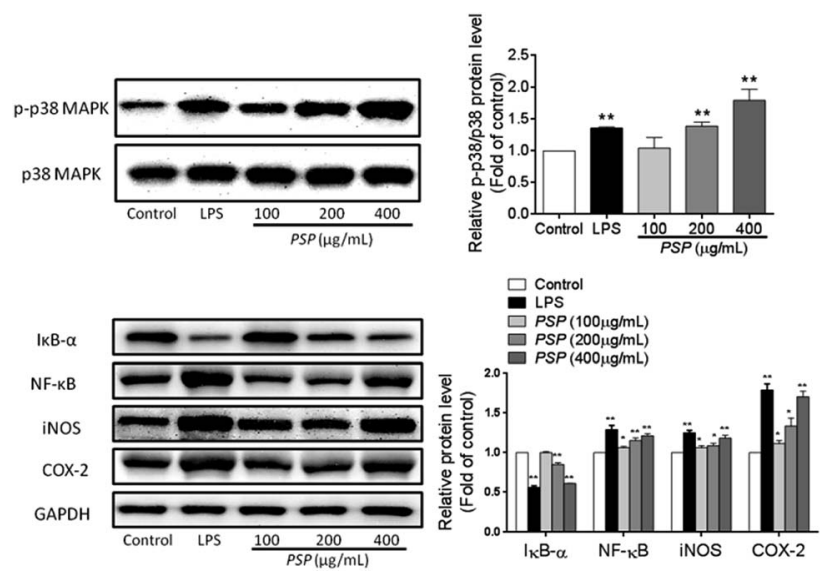

Fig. 7 RAW 264.7 cells were incubated with PSP $\left(400 \mu \mathrm{g} \mathrm{mL}^{-1}\right)$ or LPS $\left(1 \mu \mathrm{g} \mathrm{mL}^{-1}\right)$ for $30 \mathrm{~min}$. PSP induced phosphorylation of p38 MAPK and the phosphorylation of p38 MAPK was determined by Western blot. PSP induced degradation of $1 \kappa B-\alpha$ for 30 min and increased iNOS, COX-2 and NF- $\kappa B$ expression for $6 \mathrm{~h}$. These results were expressed as mean $\pm \mathrm{SD}, n=3 .{ }^{*} p<0.05,{ }^{* *} p<0.01$, compared to the control group.

\section{Discussion}

Water-soluble polysaccharides were extracted from Polygonatum sibiricum using hot water extraction and ethanol precipitation. The mass yield of crude polysaccharides was $4.45 \%(\mathrm{w} / \mathrm{w})$, which was higher than $2.48 \%$ reported by Zhang et al. ${ }^{15}$ as well as $4.40 \%$ reported by Liu $e t a l .{ }^{10}$ Several studies have been reported on the effects of immunomodulation, infection prevention, improvement of intestinal environment, and cancer suppression.9,10,16 Our previous findings regarding direct immunostimulation showed that PSP can significantly reverse the increase of serum IL-10 and decline of serum IL-2, IL-8 and TNF- $\alpha$ to a normal range in a dose-dependent manner in Cytreated Balb/c mice. ${ }^{9}$ This suggests that PSP may have regulatory effects on the enhancement of immunity through these cytokine secretions and that this results in the subsequent elicitation of stronger immune responses. In addition, the administration of PSP was found to reverse immunosuppression by promoting the development of immune organs, lymphocyte proliferation and macrophage phagocytosis, as well as by regulating the levels of serum cytokines in immunosuppressive mice. The mechanisms by PSP stimulates immune reactions are unclear. In the present study, we describe the alternative mechanisms of PSP to modulate the immune response by evaluating its capability in macrophages. PSP in LPS-activated RAW 264.7 cells inhibits the production of key pro-inflammatory mediators, such as NO, TNF- $\alpha$ and IL-6. These effects were accompanied by downregulation of the NF- $\kappa \mathrm{B}$ activity and inactivation of the MAPK signaling pathway without cytotoxicity.

Macrophages are important components of the immune system and constitute, together with neutrophils, the front-line phagocytes which act to eliminate pathogens from the bloodstream and tissues. ${ }^{17}$ Activation of macrophages is essential for the host defense system. Accumulating evidence suggests that autophagy, a cellular homeostatic mechanism is an important component in macrophage activity and hence immune functioning. Reactive oxygen species (ROS) the downstream products of activated NF- $\mathrm{KB}$, are of major importance for host defense but can also induce cell and tissue damage. Normally, the production and exclusion systems of ROS in macrophages help maintain balance. The increase of ROS production or the declined ability to scavenge ROS causes oxidative stress injury that is implicated in the pathogenesis of different types of diseases. Many studies consider ROS as a new secondary messenger that may be involved in multiple signal transduction pathways, which has become a new research focus in signal transduction pathways. The radical scavenging test (DPPH and ABTS) was conducted to investigate the radical scavenging activities of polysaccharides. ${ }^{18}$ This study demonstrated that the PSP can effectively scavenge free radicals with high concentrations which may contribute to the protection of macrophages by scavenging ROS generated from cytokines and growth factors. ${ }^{19}$ Moreover, deformation of macrophages, especially the emergence of dendritic-like morphology, often means the activation of macrophages has occurred. ${ }^{19}$ In this study, the PSP-treated 
cells showed similar morphological changes as cell treated with LPS with nearly half of the cells showing polygonal and dendritic-like morphology.

The production of NO is the killing mechanism of an activated macrophage, which works in combination with hydrogen peroxide or superoxides. ${ }^{19}$ Peroxynitrite radicals produced from this reaction can kill phagocytosed microbes in the macrophage. NO is also considered to be one of the most important mediators directly involved in tumor-cell killing in addition to eliminating microbes. ${ }^{20}$ Upon stimulation of external factors, macrophages can be activated and thereby activate the various cytokines (TNF- $\alpha$, IL-1, IL- 6 and IL-12), interferon (IFN- $\gamma$ ), and chemokines which ultimately stimulate the host's immune system. ${ }^{21}$ In this study, PSP significantly increased serum TNF- $\alpha$ and IL-6 levels in RAW 264.7 cells and LPS. The transcription of genes encoding TNF- $\alpha$ and IL- 6 and the secretion of TNF- $\alpha$ and IL- 6 are barely detectable in normal cells. However, the transcriptional and secretional levels of TNF- $\alpha$ and IL- 6 in the PSP/LPS-induced cells are several times higher than those in the control group. These findings suggest that PSP may have a favorable effect on the immunological status in RAW 264.7 cells. TNF$\alpha$ and IL- 6 transcription have been documented to be influenced by both MAPK and NF- $\kappa$ B pathway. ${ }^{22}$ The transcription factor $\mathrm{NF}-\kappa \mathrm{B}$ plays a central role in the regulation of many immune and inflammatory responses. ${ }^{23} \mathrm{NF}-\kappa \mathrm{B}$ forms an inactive cytoplasmic complex together with its inhibitor (I $\kappa$ B$\alpha$ ) in unstimulated cells. Upon stimulation, the degradation of $\mathrm{I} \kappa \mathrm{B}-\alpha$ results in the release of NF- $\kappa \mathrm{B}$, and the p65 subunit then translocates from the cytoplasm to the nucleus. The p38 MAPK signaling pathway plays an important role in the immune response by inducing the expression of key inflammatory mediators. Although the relationship between MAPKs and NF- $\mathrm{KB}$ in inflammation has not been elucidated, previous studies have demonstrated that inflammatory stimuli activate MAPKs, followed by up-regulation of the transcription of pro-inflammatory cytokines and mediators. ${ }^{24-26}$ In particular, the MAPK pathway turns out to be involved in the activation of transcription factors (NF- $\kappa \mathrm{B}$ and AP-1). We observed that MAPKs were activated in the macrophage cell line RAW264.7 by PSP and LPS (Fig. 7). This activation of MAPKs, possibly through TLR4 and/or TLR2, seems to be involved in the expression of cytokines in RAW264.7 cells. TLR2 is activated primarily by peptidoglycan and lipoprotein, while TLR4 is predominantly activated by LPS and lipoteichoic acid. ${ }^{27}$ Polysaccharides with large molecular mass cannot penetrate the cell membrane, ${ }^{28}$ therefore, it has been suggested that the cellular activation could be caused by the surface binding of PSP to a receptor(s) specifically expressed on macrophages. As mentioned above, PSP possesses the same biological activity as LPS, which shares a cell-type specificity closely related to TLR4. Therefore, we hypothesize that TLR4 is involved in the mechanisms of immunological effects of PSP on RAW 264.7 cells as a likely receptor candidate. This structurally diverse class of macromolecules can profoundly affect biological activities in macrophages. On the basis of the results above, we found that PSP has the same biological activity as other polysaccharides (Phellinus baumii mycelia, pine-mushroom, and Angelan), ${ }^{29-31}$ and probably regulates NF- $\kappa$ B/MAPKs with the same mechanism (TLR4 and/or TLR2 pathway). Much more research is required to elucidate the relationship of the structure and activity of purified polysaccharides and their role in the immune response.

\section{Materials and methods}

\subsection{Materials and reagents}

The rhizome of Polygonatum sibiricum (Origin: Hebei, China) was supplied by Changsha central hospital (Hunan, China). Lipopolysaccharide (LPS) and thiazolyl blue (MTT) were purchased from Beijing Solarbio Science \& Technology Co., Ltd. (Beijing, China). LDH and nitric oxide commercial kits were obtained from Nanjing Jiancheng Bio-engineering Institute (Nanjing, China). Cytokine detecting ELISA kits were purchased from Shanghai Westang Bio-Tech Co., Ltd. (Shanghai, China). Specific primers (IL-6, TNF- $\alpha$, GAPDH) were purchased from Biosune Biotechnology Co., Ltd. (Shanghai, China). All the other chemicals used were of analytical grade.

\subsection{Preparation of polysaccharide sample}

The polysaccharide sample (PSP) were purified and isolated as our previous study. ${ }^{9}$ In brief, the rhizome of Polygonatum sibiricum was dried and powdered (40 meshes). The dried powder $(100 \mathrm{~g})$ was weighed accurately and refluxed by $95 \%(\mathrm{v} / \mathrm{v})$ ethanol at $45^{\circ} \mathrm{C}$ for $3 \mathrm{~h}$. Then the filter residue was boiled in 10 volume of distilled water $(\mathrm{v} / \mathrm{w})$ for $1 \mathrm{~h}$ and extracted three times at $80^{\circ} \mathrm{C}$. The supernatant was concentrated using a rotary evaporator. Anhydrous ethanol was slowly added to the condensation until reaching the end concentration of $80 \%(\mathrm{v} / \mathrm{v})$ to precipitate the macromolecules. The precipitate was treated with absolute acetone, Sevag reagent and activated carbon to yield PSP.

\subsection{Identification of polysaccharide}

Total carbohydrate content of the PSP was estimated by the anthrone-sulfuric acid colorimetry method with glucose as standard. Fehling, Molisch, precipitation, biuret, ninhydrin analysis method were employed to identify PSP.

\subsection{Radical scavenging activity}

DPPH method. The measurement of DPPH radical scavenging activity was carried out according to the method described by Shimada et al. with slightly modifications. ${ }^{\mathbf{1 2}}$ Briefly, $1 \mathrm{~mL}$ of PSP at various concentrations $(0.1,0.2,0.5$, 1.0, 2.0, 3.0, 5.0 and $10.0 \mathrm{mg} \mathrm{mL}{ }^{-1}$ ) were added to $0.5 \mathrm{~mL}$ of DPPH radical in methanol $(0.1 \mathrm{mM})$. After mixed well, the solution was reacted at room temperature in the dark for $30 \mathrm{~min}$, and the reduction of DPPH was calculated by an absorbance at $517 \mathrm{~nm}$ according to the following formula: scavenging effect $(\%)=(\mathrm{OD}$ value of sample at $517 \mathrm{~nm} / \mathrm{OD}$ value of control at $517 \mathrm{~nm}) \times 100 \%$. 
ABTS method. The quantity of antioxidant in the test sample is inversely proportional to the ABTS radical development. ${ }^{13}$ ABTS is generated by mixing $0.2 \mathrm{~mL}$ of $7 \mathrm{mM}$ ABTS with 0.2 of $2.45 \mathrm{mM}$ potassium persulfate and stored in the dark at room temperature for $16 \mathrm{~h}$, then diluted with ethanol to achieve an absorbance of $0.7 \pm 0.05$ at $734 \mathrm{~nm}$. The radical scavenging activity is assessed by mixing $2 \mathrm{~mL}$ of ABTS solution with different concentrations of sample $(0.1,0.2$, $\left.0.5,1.0,2.0,3.0,5.0,10.0 \mathrm{mg} \mathrm{mL} \mathrm{m}^{-1}\right)$. After $6 \mathrm{~min}$, the percentage inhibition at $734 \mathrm{~nm}$ was calculated for each concentration relative to blank absorbance.

\subsection{Experimental design in vitro}

Cell lines and culture. RAW 264.7 cells were procured from the Shanghai Institute of Cell Biology, Chinese Academy of Sciences (Shanghai, China). The cells were maintained $\left(37^{\circ} \mathrm{C}\right.$, $5 \% \mathrm{CO}_{2}$ ) in DMEM medium (Hyclone, Thermo Fisher Scientific, Beijing, China) supplemented with $10 \%$ fetal bovine serum (Bioind, Australia), penicillin $\left(100 \mathrm{U} \mathrm{mL}^{-1}\right)$ and streptomycin $\left(100 \mu \mathrm{g} \mathrm{mL}^{-1}\right)$.

Cell viability assay. The cell viability was determined by the colorimetric MTT assay. RAW 264.7 cells were seeded in 96-well plates at a density of $2 \times 10^{4}$ cells per well and pre-incubated in the growth medium with required concentrations of PSP (0.0, 5.0, 10.0, 25.0, 50.0, 100, 200, 400, $800 \mu \mathrm{g} \mathrm{mL}{ }^{-1}$ ) added. After $24 \mathrm{~h}$ incubation, MTT ( $5 \mathrm{mg} \mathrm{mL}^{-1}$ ) was added to each well and incubated for additional $4 \mathrm{~h}$. The supernatant was aspirated and $100 \mu \mathrm{L}$ of DMSO was added to each well. Absorbance was measured at $570 \mathrm{~nm}$ by a microplate reader.

LDH activity assay. The supernatant were used for the measurement of the protein, lactate dehydrogenase (LDH) activity were conducted according to the instructions of commercial kits via spectrophotometric methods. In brief, supernatant $(0.05 \mathrm{~mL})$ were transferred to the corresponding wells of a 96-well enzyme immunoassay plate with matrix buffer and coenzyme I mixture, and after $15 \mathrm{~min}$ of incubation at $37{ }^{\circ} \mathrm{C}$, 2,4-dinitrophenylhydrazine was added. Another $15 \mathrm{~min}$ incubation, $0.4 \mathrm{~mol} \mathrm{~L}^{-1} \mathrm{NaOH}$ was added to stop the enzyme reaction, and the absorbance at $450 \mathrm{~nm}$ was measured. The cytotoxicity of a test detergent was defined as the release of $\mathrm{LDH}$ from lysed cells as a percentage of the total LDH activity. The enzyme activity was expressed in nanomoles per milligram of protein.

Nitric oxide production. Adherent RAW 264.7 cells were treated with $100 \mu \mathrm{g} \mathrm{mL} \mathrm{m}^{-1}$ (PSP-L), $200 \mu \mathrm{g} \mathrm{mL} \mathrm{mL}^{-1}$ (PSP-M), $400 \mu \mathrm{g}$ $\mathrm{mL}^{-1}$ (PSP-H) at increasing concentrations of PSP in the growth medium at $37{ }^{\circ} \mathrm{C}$ and LPS $\left(1 \mu \mathrm{g} \mathrm{mL}{ }^{-1}\right)$ was used as positive control in 24 -well plates. After $24 \mathrm{~h}$ incubation, the nitric oxide production was assayed using commercial kits. The absorbance at $550 \mathrm{~nm}$ was measured by colorimetry.

Cytokine secretion and quantification. To investigate the effect of PSP on IL-6 and TNF- $\alpha$ production, RAW 264.7 cells were grown in 24-well plates induced with PSP $(100,200,400 \mu \mathrm{g}$ $\left.\mathrm{mL}^{-1}\right)$ and LPS $\left(1 \mu \mathrm{g} \mathrm{mL}{ }^{-1}\right)$ for $24 \mathrm{~h}$. The supernatants were collected by centrifugation at $4000 \mathrm{~g}$ for $10 \mathrm{~min}$, and the levels of cytokine (IL- 6 and TNF- $\alpha$ ) in the serum was determined by colorimetry according to provided procedures. The colorimetry was read with enzymatic-reader using the mouse ELISA kit according to the instructions.

RNA extraction and RT-PCR. Briefly, total RNA was extracted and purified from the RAW 264.7 cells media using the Trizol reagent (Invitrogen, USA). The RNA content of the samples was quantified by measuring the absorbance at $260 \mathrm{~nm}$. The RNA was converted into cDNA using a ReverTra Ace® ${ }^{\circledR}$ qPCR RT Kit (TOYOBO, Osaka, Japan). The cDNA $(1 \mu \mathrm{L})$ was then amplified for 35 PCR cycles using the C1000 Touch ${ }^{\mathrm{TM}}$ Thermal Cycler Real-Time System (Bio-RAD, USA) and the SYBR® Green Realtime PCR Master Mix (TOYOBO, Osaka, Japan) according to the manufacturer's protocol. Real-time PCR reactions were performed in duplicate for both the target and control genes. For each combination of primers, the PCR amplification kinetics were determined and the number of cycles corresponding to the plateau was counted. Glyceraldehyde-3phosphate dehydrogenase (GAPDH) was used as a house keeping gene.

Specific primers:

IL-6 (forward primer: 5-TAGTCCTTCCTACCCCAATTTCC-3, reverse primer: 5-TCTCAGCCCTCTTCAAAAACTTCTC-3),

TNF- $\alpha$ (forward primer: 5-GCATCGGTCCCCAAAGGGATG-3, reverse primer: 5-GTGGTTTGTGAGTGTGAGGGT-3),

GAPDH (forward primer: 5-GCACCGTCAAGGCTGAGAAC-3, reverse primer: 5-ATGGTGGTGAAGACGCCAGT-3).

\subsection{Assessment of NF- $\kappa B$ (p65) nuclear translocation}

Immunocytochemistry. The capability of PSP was analyzed to penetrate into the nuclei of treated RAW 264.7 cells using laser confocal microscopy to identify the inhibition of NF- $\kappa$ B. RAW 264.7 cells were incubated in $35 \mathrm{~mm}$ glass-coated wells and treated with PSP $\left(400 \mu \mathrm{g} \mathrm{mL}^{-1}\right)$ or LPS $\left(1 \mu \mathrm{g} \mathrm{mL}^{-1}\right)$ for $24 \mathrm{~h}$. The cells were fixed with cold acetone and ethanol $(1: 1)$ at $4{ }^{\circ} \mathrm{C}$ for $30 \mathrm{~min}$ and washed with PBS. Thereafter, the cells were blocked with $5 \%$ BSA for $30 \mathrm{~min}$ at room temperature and incubated with the NF- $\kappa$ B p65 antibody $(1: 100)$ overnight at $4{ }^{\circ} \mathrm{C}$. The cells were washed three times with PBS for $5 \mathrm{~min}$ and then incubated with FITC-conjugated goat anti-rabbit IgG (1:100) (ZSGB-BIO, Beijing, China) for $1 \mathrm{~h}$ at room temperature. After washing in PBS for $30 \mathrm{~min}$, the cells were stained with DAPI for $10 \mathrm{~min}$. The specimen was examined and photographed by laser confocal microscopy (LSM700, ZEISS, Germany).

Western blot analysis. RAW 264.7 cells were seeded in 6-well plates and incubated with different concentrate of PSP (100, 200, $\left.400 \mu \mathrm{g} \mathrm{mL}^{-1}\right)$ and LPS $\left(1 \mu \mathrm{g} \mathrm{mL}^{-1}\right)$ for $30 \mathrm{~min}$ and $6 \mathrm{~h}$. After that, the pellets were rinsed with ice-cold phosphate-buffered saline (PBS) and lysed with RIPA buffer for $30 \mathrm{~min}$ on ice to collect total proteins for western blotting analysis. These samples were then centrifuged at $12000 \mathrm{~g}$ for $15 \mathrm{~min}$ at $4{ }^{\circ} \mathrm{C}$. The supernatants were collected and the protein levels were determined by BCA protein assay kit with BSA as standard. Total proteins ( $50 \mu \mathrm{g}$ per lane) were separated by $10 \%$ SDS-PAGE, and transferred on a polyvinylidene difluoride (PVDF) membrane. After blocking with a solution containing 5\% skim milk for $2 \mathrm{~h}$ 
at room temperature to prevent non-specific binding of antibody, membrane was incubated with the appropriate primary antibodies at $4{ }^{\circ} \mathrm{C}$ overnight. After washing, membranes were incubated with horseradish-peroxidase (HRP)-conjugated secondary antibody $(1: 10$ 000) in TBST containing 5\% milk at room temperature for $2 \mathrm{~h}$. Then, the membrane preparations were washed three times in TBST and visualized by enhanced chemiluminescence system (Merck Millipore, Darmstadt, Germany). The films were subsequently scanned, and the signal intensity of each band was determined by Alphalmager HP system (Cell Biosciences, Inc., Santa Clara, CA, USA).

\subsection{Statistical analysis}

The results were presented as mean \pm SD (standard deviation). The statistical significance was analyzed by student's test using SPSS for mean differences among the samples. Differences between groups at $p<0.05$ were considered statistically significant.

\section{Conclusions}

The results of our in vitro assays demonstrated that PSP can activate macrophages in a concentration-dependent manner and enhance the functions of macrophages via NF- $\kappa \mathrm{B}$ and p38 MAPK pathways. Thus, PSP can be regarded as a promising candidate as an immunomodulator. In order to fully develop the resources and extend the potential use of Polygonatum sibiricum in immune biomedicine, further studies of the structure and activity relationship are essential to shed light on the detailed upstream mechanisms based on these findings.

\section{Conflicts of interest}

There are no conflicts to declare.

\section{Acknowledgements}

This work was supported financially by Key research and development program of Shandong Province (No. 2018GSF118024) and Natural Science Foundation of Shandong Province (ZR2019BH039).

\section{Notes and references}

1 J. E. Ramberg, E. D. Nelson and R. A. Sinnott, Nutr. J., 2010, 9, 1-22.

2 Y. Meng, J. Yan, G. Yang, Z. Han, G. Tai, H. Cheng and Y. Zhou, Carbohydr. Polym., 2018, 183, 207-218.

3 D. Hirayama, T. Iida and H. Nakase, Int. J. Mol. Sci., 2018, 19, 92.

4 I. A. Schepetkin and M. T. Quinn, Int. Immunopharmacol., 2006, 6, 317-333.

5 K. S. Devi and T. K. Maiti, Recent Pat. Biotechnol., 2016, 10, 72-78.

6 R. Maeda, T. Ida, H. Ihara and T. Sakamoto, Journal of the Agricultural Chemical Society of Japan, 2012, 76, 501-505.
7 N. Kunworarath, N. Rangkadilok, T. Suriyo, A. Thiantanawat and J. Satayavivad, J. Ethnopharmacol., 2016, 179, 156-161.

8 J. J. Baldassare, Y. Bi and C. J. Bellone, J. Immunol., 1999, 162, 5367.

9 N. Liu, Z. Dong, X. Zhu, H. Xu and Z. Zhao, Int. J. Biol. Macromol., 2017, 107, S0141813016309941.

10 L. Liu, Q. Dong, X. T. Dong, J. N. Fang and K. Ding, Carbohydr. Polym., 2007, 70, 304-309.

11 Y. Fang, C. X. Wang and D. P. Xu, Food \& Fermentation Industries, 2010.

12 L. I. Li, L. N. Tian, Z. X. Ren and Z. J. Long, J. Mol. Biol., 2006, 362, 430-440.

13 K. Shimada, K. Fujikawa, K. Yahara and T. Nakamura, J. Agric. Food Chem., 1992, 40, 945-948.

14 S. Zhang, X. Z. Li, Z. P. Wu and C. T. Kuang, Adv. Mater. Res., 2012, 550-553, 1545-1549.

15 Z. Huixue, C. Yuze, C. Lixia, W. Jianjian, T. Qinghua, W. Ning, L. Zhaojun, L. Jie, W. Na and W. Xiaokun, Carbohydr. Polym., 2015, 117, 879-886.

16 G. U. Hongmei, Y. Meng and P. U. Qiang, Chin. J. Appl. Environ. Biol., 2003, 9, 21-23.

17 S. Gordon and F. O. Martinez, Immunity, 2010, 32, 593-604.

18 K. Zhong, Q. Wang, Y. He and X. He, Int. J. Biol. Macromol., 2010, 47, 356-360.

19 D. S. Jang, B. S. Kang, Y. R. Shi, I. M. Chang, K. R. Min and Y. Kim, Biochem. Pharmacol., 1999, 57, 705-712.

20 A. H. Klimp, E. G. E. de Vries, G. L. Scherphof and T. Daemen, Crit. Rev. Oncol. Hematol., 2002, 44, 143-161.

21 I. K. Sen, A. K. Mandal, R. Chakraborty, B. Behera, K. K. Yadav, T. K. Maiti and S. S. Islam, Carbohydr. Polym., 2014, 101, 188-195.

22 J. Li, W. Qian, Y. Xu, G. Chen, G. Wang, S. Nie, B. Shen, Z. Zhao, C. Liu and K. Chen, Carbohydr. Polym., 2015, 130, 97-103.

23 S. J. Park, Y. W. Kim, M. K. Park, S. H. Byun, C. K. Sang and J. R. Lee, Inflammation, 2015, 39, 727-734.

24 J. Guiyuan, Y. Qinhe, H. Jing, G. Lina, C. Xiang, H. Jianping, L. Liang and J. Zhuoqin, Int. Immunopharmacol., 2011, 11, 762-768.

25 S. Paul, A. M. Rimando, J. L. Hong, J. Yan, B. S. Reddy and N. Suh, Cancer Prev. Res., 2009, 2, 650-657.

26 Q. Yu, K. W. Zeng, X. L. Ma, F. J. Song, Y. Jiang, P. F. Tu and X. M. Wang, Int. Immunopharmacol., 2016, 38, 104-114.

27 H. D. Brightbill, D. H. Libraty, S. R. Krutzik, R. B. Yang, J. T. Belisle, J. R. Bleharski, M. Maitland, M. V. Norgard, S. E. Plevy and S. T. Smale, Science, 1999, 285, 732-736.

28 S. B. Han, Y. D. Yoon, H. J. Ahn, H. S. Lee, C. W. Lee, W. K. Yoon, S. K. Park and H. M. Kim, Int. Immunopharmacol., 2003, 3, 1301-1312.

29 Q. Xue, J. Sun, M. Zhao, K. Zhang and R. Lai, World J. Microbiol. Biotechnol., 2011, 27, 1017-1023.

30 Y. J. Jeon and H. M. Kim, Int. Immunopharmacol., 2001, 1, 1331-1339.

31 J. Y. Kim, S. E. Byeon, Y. G. Lee, J. Y. Lee, J. Park, E. K. Hong and J. Y. Cho, J. Microbiol. Biotechnol., 2008, 18, 95-103. 